\title{
Lymphocyte-suppressing action of simvastatin in patients with isolated hypertriglyceridemia
}

\author{
Robert Krysiak, Bogusław Okopień \\ Department of Internal Medicine and Clinical Pharmacology, Medical University of Silesia, Medyków 18, \\ PL 40-752 Katowice, Poland \\ Correspondence: Robert Krysiak, e-mail: r.krysiak@interia.pl
}

\begin{abstract}
:
Background: No previous study examined whether statins affect lymphocyte cytokine release in patients with isolated hypertriglyceridemia.

Methods: The study included 46 patients with elevated triglyceride levels and peripheral artery stenosis, randomly assigned to receive simvastatin or placebo. Plasma lipids, glucose homeostasis markers, plasma C-reactive protein and lymphocyte cytokine release were measured at baseline and at the end of the treatment.

Results: Ninety-day simvastatin treatment reduced lymphocyte release of TNF- $\alpha$, interleukin- 2 and interferon- $\gamma$, which was accompanied by a decrease in plasma C-reactive protein.

Conclusion: The obtained results suggest that statins produce lymphocyte-suppressing and systemic anti-inflammatory effects in patients with isolated hypertriglyceridemia.
\end{abstract}

Key words:

statins, coronary artery disease, hypertriglyceridemia, lymphocytes, proinflammatory cytokines, risk factors

\begin{abstract}
Abbreviations: CRP - C-reactive protein, ELISA - enzyme-linked immunosorbent assay, HDL - high density lipoproteins, HMGCoA - 3-hydroxy-3-methylglutaryl coenzyme A, HOMA-IR the homeostatic model assessment - insulin resistance, hsCRP - high sensitivity C-reactive protein, LDL - low density lipoproteins, TNF- $\alpha$ - tumor necrosis factor- $\alpha$
\end{abstract}

\section{Introduction}

Large clinical trials have demonstrated that 3-hydroxy3-methylglutaryl coenzyme A (HMG-CoA) reductase inhibitors, or statins, markedly reduce morbidity and mortality when used in the primary and secondary prevention of cardiovascular diseases [14, 16]. The benefits of statin therapy in cardiovascular diseases can be explained not only by the lipid-lowering potential of statins but also by nonlipid-related mechanisms (so-called "pleiotropic effects"), which include regulation of the growth and migration of smooth muscle cells, improvement of the functioning of vascular endothelium, as well as the inhibitory effect on coagulation, fibrinolysis and platelet activities [2, 20]. We have observed that one of the targets for statin action are lymphocytes, cells playing an important role in the pathogenesis of atherosclerosis and the development of its complications [4, 19]. Apart from patients with isolated hypercholesterolemia [10, 11], lymphocyte-suppressing effects of HMG-CoA reductase inhibitors were observed in patients with mixed dyslipidemia [8], impaired fasting glucose [9] and overt diabetes [6]. However, no previous study examined 
whether statin affects lymphocyte cytokine release in patients with selectively elevated plasma triglycerides. Hypertriglyceridemia is associated with an increased risk of the earlier development and accelerated progression of atherosclerosis-related disorders [3, 17]. A meta-analysis of the results of 21 studies showed that each $90 \mathrm{mg} / \mathrm{dl}$ increase in plasma triglycerides was associated with a $32 \%$ increase in coronary artery disease events in men and a $76 \%$ increase in coronary artery disease events in women [1]. In our recent study [7], bezafibrate effectively and lipid-independently inhibited lymphocyte cytokine release in patients with isolated hypertriglyceridemia, and therefore, we decided to investigate whether similar effects are produced by HMG-CoA reductase inhibitors.

\section{Materials and Methods}

The patients with lower extremity arterial stenosis were eligible for the study if they were between 30 and 70 years old, had a family history of coronary artery disease (but personally did not suffer from this disorder), and met the following criteria of isolated hypertriglyceridemia: triglyceride levels between 200 and $500 \mathrm{mg} / \mathrm{dl}$, total cholesterol less than $200 \mathrm{mg} / \mathrm{dl}$ and LDL cholesterol less than $130 \mathrm{mg} / \mathrm{dl}$. These patients $(n=46)$ were randomly assigned to receive simvastatin (40 mg daily, $\mathrm{n}=23$ ), or placebo $(\mathrm{n}=23$ ). The exclusion criteria were as follows: any form of coronary artery disease, stroke within 6 months preceding the study, symptomatic congestive heart failure, diabetes, moderate or severe arterial hypertension (ESC/ESH grade 2 or 3), any acute and chronic inflammatory processes, autoimmune disorders, thyroid diseases, chronic pancreatitis, impaired renal or hepatic function, nephrotic syndrome, liver and biliary tract diseases, body mass index above $35 \mathrm{~kg} / \mathrm{m}^{2}$, treatment with any hypolipemic agents within 3 months, concomitant treatment with other drugs known either to affect plasma lipid levels or to interact with statins, and poor patient compliance.

The study protocol was approved by the Bioethical Committee of the Medical University of Silesia and informed consent was obtained from all participants before enrollment. Simvastatin or placebo were administered once daily at bedtime for 90 days and no changes in medication dosage were allowed throughout the study. Treatment safety was monitored at entry and then fortnightly throughout the study. Overt myopathy, elevated levels of aminotransferases ( $>3$ times the upper limit of normal) and of creatine kinase $(>10$ times the upper limit of normal) were considered an indication for withdrawal of treatment. Compliance was monitored during each visit by tablet count and was regarded as satisfactory if the number of tablets taken by a patient ranged from 90 to $110 \%$.

Laboratory investigations were performed at baseline and at the end of the treatment. Venous blood samples were drawn from antecubital vein, after a 12-h overnight fast, in a quiet temperature controlled room $\left(24-25^{\circ} \mathrm{C}\right)$ between 8.00 and 9.00 a.m. (to avoid possible circadian fluctuations in the parameters studied). To minimize analytical errors, all measurements were carried out in duplicate. Plasma lipids, glucose, and insulin were assayed by routine laboratory techniques (bioMerieux France; Beckman, Palo Alto, CA; Linco Research Inc, St Charles, MO; Bayer Ames Technicon, Tarrytown, NY, USA). LDL cholesterol levels were measured directly. Fasting plasma glucose and insulin levels were used to calculate the homeostatic model assessment - insulin resistance (HOMA-IR) index [fasting serum glucose $(\mathrm{mg} / \mathrm{dl}) \times$ fasting insulin level $(\mu \mathrm{U} / \mathrm{ml}) / 405]$. Plasma levels of CRP were measured using a high-sensitivity monoclonal antibody assay (hsCRP) (MP Biomedicals, Orangeburg, NY, USA). Cultures of phytohemagglutinin-stimulated $\mathrm{T}$ cells were conducted in triplicate as described previously [11]. Lymphocyte release of TNF- $\alpha$, interferon- $\gamma$ and interleukin- 2 was measured using commercial ELISA kits (R\&D, McKinley Place N.E. Minneapolis, MN, USA) according to the manufacturer's instructions. The minimum detectable levels for hsCRP, TNF- $\alpha$, interferon- $\gamma$ and interleukin- 2 were $0.1 \mathrm{ng} / \mathrm{ml}, 4.4 \mathrm{pg} /$ $\mathrm{ml}, 15 \mathrm{pg} / \mathrm{ml}$ and $8 \mathrm{pg} / \mathrm{ml}$, respectively.

The Kolmogorov-Smirnov test was used as the first statistical analysis approach to verify data distribution normality. Because of skewed distributions, values for the HOMA-IR, hsCRP and cytokines were natural-log transformed to meet the assumptions of parametric tests. Both groups were compared by $t$-tests for independent samples. The differences between baseline and post-treatment values within the same treatment group were compared with the Student's paired $t$-test. Kendall's $\tau$ test was used to evaluate the relationship between metabolic variables and inflammatory mediators. A p-value less than 0.05 was considered significant. 


\section{Results}

Both groups were similar with regard to age, sex, weight, medical background and clinical characteristics. The mean values of plasma lipids, glucose, HOMA-IR, plasma hsCRP and lymphocyte cytokine release were all comparable between the study groups (Tab. 1).

One patient was withdrawn from the study because of simvastatin-induced myalgia, while another patient receiving placebo left the study due to noncompliance with the study protocol. No significant adverse effects were observed in the remaining patients, and there were no other discontinuations due to adverse events during the study course.

Simvastatin administered to hypertriglyceridemic patients reduced total and LDL cholesterol, tended to reduce triglycerides and to increase HDL cholesterol, and did not affect plasma glucose or HOMA-IR. Moreover, simvastatin inhibited lymphocyte release of TNF- $\alpha$, interleukin-2 and interferon- $\gamma$ (Tab. 2), as well as decreased plasma levels of hsCRP. In placebo-

Tab. 1. Baseline characteristics of patients ${ }^{1}$

\begin{tabular}{lcc}
\hline & Placebo & Simvastatin \\
\hline Number of patients & 22 & 22 \\
Age [years; mean (SD)] & $48(4)$ & $49(5)$ \\
Women [\%] & 41 & 45 \\
Body mass index [kg/m²; mean (SD)] & $28.1(2.7)$ & $28.3(2.4)$ \\
Waist circumference [cm; mean (SD)] & $102(7)$ & $104(7)$ \\
Smokers [\%] & 27 & 32 \\
Mild hypertension [\%] & 32 & 32 \\
Total cholesterol [mg/dl; mean (SD)] & $167(16)$ & $170(17)$ \\
LDL cholesterol [mg/dl; mean (SD)] & $97(9)$ & $99(10)$ \\
HDL cholesterol [mg/dl; mean (SD)] & $47(5)$ & $47(4)$ \\
Triglycerides [mg/dl; mean (SD)] & $283(36)$ & $291(37)$ \\
Fasting glucose [mg/dl; mean (SD)] & $89(4)$ & $90(3)$ \\
HOMA-IR [mean (SD)] & $2.3(0.5)$ & $2.2(0.4)$ \\
hsCRP [mg/l; mean (SD)] & $1.8(0.4)$ & $2.0(0.4)$ \\
TNF- $\alpha$ release [pg/ml; mean (SD)] & $298(35)$ & $289(34)$ \\
Interferon- $\gamma$ release [ng/ml; mean (SD)] & $42.1(7.3)$ & $46.1(6.9)$ \\
Interleukin-2 release [ng/ml; mean (SD)] & $4.8(0.7)$ & $4.9(0.6)$ \\
\hline
\end{tabular}

${ }^{1}$ Only data of 44 individuals who completed the study were included in the final analyses treated patients, lipid profile, plasma glucose, HOMA-IR, plasma hsCRP and lymphocyte cytokine release remained at the similar levels throughout the study. Simvastatin was superior to placebo in the extent of the reduction in plasma levels of total cholesterol, LDL cholesterol and hsCRP, as well as in the magnitude of the reduction in lymphocyte cytokine release.

At entry, there were relationships between plasma hsCRP and lymphocyte cytokine release ( $\mathrm{r}$ values between 0.49 and $0.56, \mathrm{p}<0.001)$. Apart from the association between triglycerides and TNF- $\alpha$ release $(r=$ $0.46, p<0.01$ ), baseline plasma lipids and glucose homeostasis markers did not correlate with baseline hsCRP and lymphocyte secretory function. Simvastatin-induced changes in hsCRP correlated with its action on lymphocyte release of TNF- $\alpha(\mathrm{r}=0.53, \mathrm{p}<$ $0.001)$, interleukin-2 $(r=0.56, p<0.001)$ and interferon- $\gamma(\mathrm{r}=0.58, \mathrm{p}<0.001)$. The reduction in hsCRP and lymphocyte cytokine release was unrelated to the degree of lipid profile improvement and to simvastatin action on glucose metabolism markers.

\section{Discussion}

This study revealed that simvastatin treatment of patients with isolated hypertriglyceridemia is associated with an inhibitory effect on lymphocyte secretory function. Taking into account the association between high plasma levels of TNF- $\alpha$, interferon- $\gamma$ and interleukin-2 and the increased risk of cardiovascular events $[15,18]$, simvastatin-induced decrease in lymphocyte cytokine release may lead to a reduction in morbidity and mortality related to cardiovascular diseases. Interestingly, the same dose of simvastatin as in our study administered to at risk patients reduced the number of cardiovascular events in the Heart Protection Study [5], which is to date the largest study investigating statin use in the prevention of cardiovascular disease.

Lymphocyte-suppressing effects of simvastatin correlated with its impact on plasma levels of hsCRP, considered a highly sensitive marker of low-grade vascular inflammation and a protein directly involved atherogenesis [13]. This systemic anti-inflammatory effect of simvastatin, observed previously in patients suffering from different clinical entities [12] but de- 
Tab. 2. Effect of simvastatin on plasma lipids, glucose homeostasis markers, plasma hsCRP and lymphocyte cytokine release in patients with isolated hypertriglyceridemia

\begin{tabular}{|c|c|c|}
\hline Variable & $\begin{array}{c}\text { Placebo } \\
\text { Mean (SD) }[\Delta \%]\end{array}$ & $\begin{array}{c}\text { Simvastatin } \\
\text { Mean (SD) }[\Delta \%]\end{array}$ \\
\hline $\begin{array}{l}\text { Total cholesterol }[\mathrm{mg} / \mathrm{dl}] \\
\text { Before randomization } \\
\text { After } 90 \text { days of treatment }\end{array}$ & $\begin{array}{c}167(16) \\
165(15)[-1]\end{array}$ & $\begin{array}{c}170(17) \\
134(14)[-21]^{\star \star \star \# \# \#}\end{array}$ \\
\hline $\begin{array}{l}\text { LDL cholesterol }[\mathrm{mg} / \mathrm{dl}] \\
\text { Before randomization } \\
\text { After } 90 \text { days of treatment }\end{array}$ & $\begin{array}{c}97(9) \\
94(9)[-3]\end{array}$ & $\begin{array}{c}99(10) \\
74(8)[-25]^{\star \star \star \# \#}\end{array}$ \\
\hline $\begin{array}{l}\text { HDL cholesterol }[\mathrm{mg} / \mathrm{dl}] \\
\text { Before randomization } \\
\text { After } 90 \text { days of treatment }\end{array}$ & $\begin{array}{c}47(5) \\
46(4)[-2]\end{array}$ & $\begin{array}{c}47(4) \\
53(4)[13]\end{array}$ \\
\hline $\begin{array}{l}\text { Triglycerides }[\mathrm{mg} / \mathrm{dl}] \\
\text { Before randomization } \\
\text { After } 90 \text { days of treatment }\end{array}$ & $\begin{array}{c}283(36) \\
289(40)[2]\end{array}$ & $\begin{array}{c}291(37) \\
247(28)[-15]\end{array}$ \\
\hline $\begin{array}{l}\text { Fasting glucose }[\mathrm{mg} / \mathrm{dl} \text {; mean (SD)] } \\
\text { Before randomization } \\
\text { After } 90 \text { days of treatment }\end{array}$ & $\begin{array}{c}89(4) \\
90(4)[1]\end{array}$ & $\begin{array}{c}90(3) \\
88(4)[-2]\end{array}$ \\
\hline $\begin{array}{l}\text { HOMA-IR [mean (SD)] } \\
\text { Before randomization } \\
\text { After } 90 \text { days of treatment }\end{array}$ & $\begin{array}{c}2.3(0.5) \\
2.4(0.5)[4]\end{array}$ & $\begin{array}{c}2.2(0.4) \\
2.2(0.5)[0]\end{array}$ \\
\hline $\begin{array}{l}\text { hsCRP }[\mathrm{mg} / \mathrm{l}] \\
\text { Before randomization } \\
\text { After } 90 \text { days of treatment }\end{array}$ & $\begin{array}{c}1.8(0.4) \\
1.9(0.3)[6]\end{array}$ & $\begin{array}{c}2.0(0.4) \\
1.2(0.3)[-40]^{\star \star \star \# \# \#}\end{array}$ \\
\hline $\begin{array}{l}\text { TNF- } \alpha \text { release }[\mathrm{pg} / \mathrm{ml}] \\
\text { Before randomization } \\
\text { After } 90 \text { days of treatment }\end{array}$ & $\begin{array}{c}298(35) \\
305(41)[2]\end{array}$ & $\begin{array}{c}289(34) \\
221(31)[-24]^{\star \star \# \# \#}\end{array}$ \\
\hline $\begin{array}{l}\text { Interferon- } \gamma \text { release }[\mathrm{ng} / \mathrm{ml}] \\
\text { Before randomization } \\
\text { After } 90 \text { days of treatment }\end{array}$ & $\begin{array}{c}42.1(7.3) \\
46.7(7.6)[11]\end{array}$ & $\begin{array}{c}46.1(6.9) \\
32.9(6.4)[-29]^{\star \#}\end{array}$ \\
\hline $\begin{array}{l}\text { Interleukin-2 release }[\mathrm{ng} / \mathrm{ml}] \\
\text { Before randomization } \\
\text { After } 90 \text { days of treatment }\end{array}$ & $\begin{array}{c}4.8(0.7) \\
5.2(0.8)[8]\end{array}$ & $\begin{array}{c}4.9(0.6) \\
3.8(0.5)[-22]^{\star \# \#}\end{array}$ \\
\hline
\end{tabular}

${ }^{1}$ Only data of 44 individuals who completed the study were included in the final analyses. * $p<0.05$, ${ }^{* *} p<0.01$, ${ }^{* * *} p<0.001$ vs. before randomization; \# $p<0.05$, \#\# $p<0.01$, \#\#\# $p<0.001$ vs. placebo

scribed for the first time in patients with isolated hypertriglyceridemia, may constitute one of the effector pathways affected by statin action on lymphocyte secretory function, and may be associated with the cardiovascular benefits of HMG-CoA reductase inhibitor therapy in this group of patients.

Although simvastatin reduced plasma lipids, this effect did not correlate with its lymphocyte-suppressing and CRP-lowering properties. Moreover, at entry, the only association between a metabolic variable and an inflammatory mediator was a weak correlation between plasma triglycerides and TNF- $\alpha$. Both these findings suggest that posttranslational protein prenylation, which converts proteins into more hydrophobic molecules, important for cellular signaling processes, differentiation and growth regulation, as well as membrane transport [2,20], is, at least in part, responsible for enhanced lymphocyte secretory function in hypertriglyceridemic patients, while the inhibition of protein prenylation may contribute to statininduced reduction in lymphocyte cytokine release and systemic inflammation. Interestingly, recently we have found that bezafibrate was superior to $\omega-3$ fatty acids in inhibiting lymphocyte secretory function and systemic inflammation, although both treatments effectively reduced plasma triglycerides [7]. In the pres- 
ent study, lymphocyte-suppressing effects of simvastatin were accompanied by relatively small changes in triglycerides. The results of both studies suggest that patients with isolated hypertriglyceridemia, who are unresponsive or intolerant to fibrates or having contraindications to these drugs, may benefit from combined treatment with a statin and $\omega-3$ fatty acids.

In conclusion, this study found for the first time that any HMG-CoA reductase inhibitor reduces lymphocyte secretory function in patients with isolated hypertriglyceridemia and that this action contributes to its systemic anti-inflammatory effect. Our results suggest that statin therapy, particularly in a combination with $\omega-3$ fatty acids, should be considered in selected groups of patients with isolated hypertriglyceridemia.

\section{Conflict of interest:}

The authors report no conflict of interest.

\section{Acknowledgment:}

The study was supported by the grant No. NN-1-070/06 of the Medical University of Silesia.

\section{References:}

1. Austin MA, Hokanson JE, Edwards KL: Hypertriglyceridemia as a cardiovascular risk factor. Am J Cardiol, 1998, 81, Suppl 4A, 7B-12B.

2. Blum A, Shamburek R: The pleiotropic effects of statins on endothelial function, vascular inflammation, immunomodulation and thrombogenesis. Atherosclerosis, 2009, 203, 325-330.

3. Brunzell JD: Hypertriglyceridemia. N Engl J Med, 2007, 357, 1009-1017.

4. Hansson GK: Inflammatory mechanisms in atherosclerosis. J Thromb Haemost, 2009, 7, Suppl 1, 328-331.

5. Heart Protection Study Collaborative Group: MRC/BHF Heart Protection Study of cholesterol lowering with simvastatin in 20,536 high-risk individuals: a randomised placebo-controlled trial. Lancet, 2002, 360, 7-22.

6. Krysiak R, Gdula-Dymek A, Okopień B: Effect of simvastatin and fenofibrate on cytokine release and systemic inflammation in type 2 diabetes mellitus with mixed dyslipidemia. Am J Cardiol, 2011, 107, 1010-1018.
7. Krysiak R, Gdula-Dymek A, Okopień B: The effect of bezafibrate and omega-3 fatty acids on lymphocyte cytokine release and systemic inflammation in patients with isolated hypertriglyceridemia. Eur J Clin Pharmacol, 2011, 67, 1109-1117.

8. Krysiak R, Okopień B: Lymphocyte-suppressing effect of simvastatin in mixed dyslipidemic patients but not impaired glucose tolerance patients. Pharmacol Rep, 2011, 63, 95-101.

9. Krysiak R, Okopień B: The effect of simvastatin on lymphocyte secretory function in patients with impaired fasting glucose. J Cardiovasc Pharmacol, 2010, 56, 491-497.

10. Krysiak R, Żmuda W, Okopień B: The effect of ezetimibe, administered alone or in combination with simvastatin, on lymphocyte cytokine release in patients with elevated cholesterol levels. J Intern Med, 2012, 271, $32-42$.

11. Okopień B, Krysiak R, Kowalski J, Madej A, Belowski D, Zieliński M, Labuzek K, Herman ZS: The effect of statins and fibrates on interferon-gamma and interleukin-2 release in patients with primary type II dyslipidemia. Atherosclerosis, 2004, 176, 327-335.

12. Quist-Paulsen P: Statins and inflammation: an update. Curr Opin Cardiol, 2010, 25, 399-405.

13. Ridker PM: Inflammatory biomarkers and risks of myocardial infarction, stroke, diabetes, and total mortality: implications for longevity. Nutr Rev, 2007, 65, S253-259.

14. Scandinavian Simvastatin Survival Study Group: Randomised trial of cholesterol lowering in 4444 patients with coronary heart disease: the Scandinavian Simvastatin Survival Study Group. Lancet, 1994, 344, 1383-1389.

15. Schroecksnadel K, Frick B, Winkler C, Fuchs D: Crucial role of interferon-gamma and stimulated macrophages in cardiovascular disease. Curr Vasc Pharmacol, 2006, 4, 205-213.

16. Shepherd J, Cobbe SM, Ford I, Isles CG, Lorimer AR, MacFarlane PW, McKillop JH, Packard CJ: Prevention of coronary heart disease with pravastatin in men with hypercholesterolemia. West of Scotland Coronary Prevention Study Group. N Engl J Med, 1995, 333, 1301-1307.

17. Talayero BG, Sacks FM: The role of triglycerides in atherosclerosis. Curr Cardiol Rep, 2011, 13, 544-552.

18. Tedgui A, Mallat Z: Cytokines in atherosclerosis: pathogenic and regulatory pathways. Physiol Rev, 2006, 86, $515-581$.

19. Weyand CM, Younge BR, Goronzy JJ: T cells in arteritis and atherosclerosis. Curr Opin Lipidol, 2008, 19, 469-477.

20. Zhou Q, Liao JK: Pleiotropic effects of statins. Basic research and clinical perspectives. Circ J, 2010, 74, 818-826.

Received: April 30, 2012; accepted: December 20, 2012. 